\title{
TREE SWALLOW NEST BUILT ATOP DEAD ADULT TREE SWALLOWS
}

Donald J. Stiles

20 Lake Wapta Rise SE

Calgary, AB T2J 2M9

stilesdj@shaw.ca

An interesting observation was e-mailed by Dick Stauffer, member of the Calgary Area Nestbox Monitors since 2001, on September 14, 2016. "Cleaned out the boxes this morning, had a TRES (Tree Swallow) nest built over 25 dead adults in one box, and not one had a band on." Location was $9 \mathrm{~km} \mathrm{~S}$ of Olds, $A B$, Lat/long $51^{\circ}$ $42.718^{\prime} \mathrm{N}, 114^{\circ} 07.190^{\prime} \mathrm{W}$. Figure 1 shows the nest removed intact and the Tree Swallow nest built over the dead adult Tree Swallows. In spite of the thick nest, six young were fledged. Figure 2 shows the dead Tree Swallows after being inspected individually for bands.

In 2016, Stauffer monitored 276 nest-boxes southwest of Olds, AB. This resulted in 42 first brood and three second brood nesting attempts for Mountain Bluebirds (Sialia currucoides), fledging a total of 168 young; and 148 nesting attempts for Tree Swallows (Tachycineta bicolor), fledging a total of 536 young.

Stiles noted that "It is likely that these birds were on migration in the spring farther north to a place where no banding is being done. Most monitors have found an occasional dead adult Tree Swallow (or sometimes more than one) in boxes in spring, often due to starvation caused by cold weather, but this must be a record."

\section{Additional Information of Interest:}

Spencer G. Sealy

Department of Biological Sciences

University of Manitoba

Winnipeg, MB

Capturing most of their insect prey on the wing, Tree Swallows tread a fine line when they return to the breeding grounds each spring, where they risk encountering early spring storms. The first returnees may be more likely to find a suitable nest site - abandoned woodpecker cavities or, now, nest-boxes erected for their use - but if they are hit with bad weather, the prolonged rain or snow and reduced temperatures may temporarily eliminate the flying insects. With the insects gone,

suddenly, swallows are left with little or no food. Searching for insects that are no longer there soon reduces the swallows' energy reserves and increases the risk of death by starvation. One option, however, is for swallows to seek shelter to conserve energy and "ride out" the storms, as apparently was done by the Tree Swallows found dead in Alberta early last spring, as reported above.

Tree Swallows have been recorded previously seeking temporary shelter during inclement weather in abandoned woodpecker cavities and, again, as noted above, in nest-boxes, both sites typically used for nesting by this species. ${ }^{1-5}$ During similar periods of duress, Bank Swallows (Riparia riparia) may seek holes or burrows in embankments, whereas Barn Swallows (Hirundo rustica) huddle in old nests in barns or under bridges, thus, also using species-specific nest sites. ${ }^{3,5}$ Remaining still in a cavity or nest-box conserves energy, but an individual's heat loss would be reduced

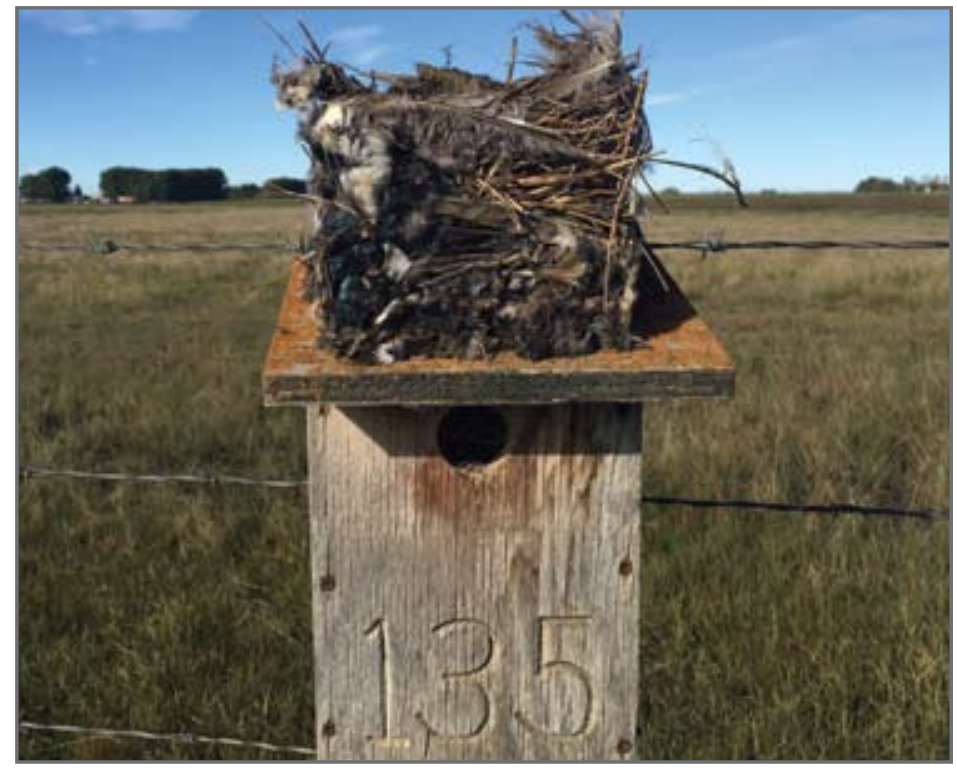

Figure 1: The nest removed intact and the Tree Swallow nest built over the dead adult Tree Swallows. Photo credit: Dick Stauffer

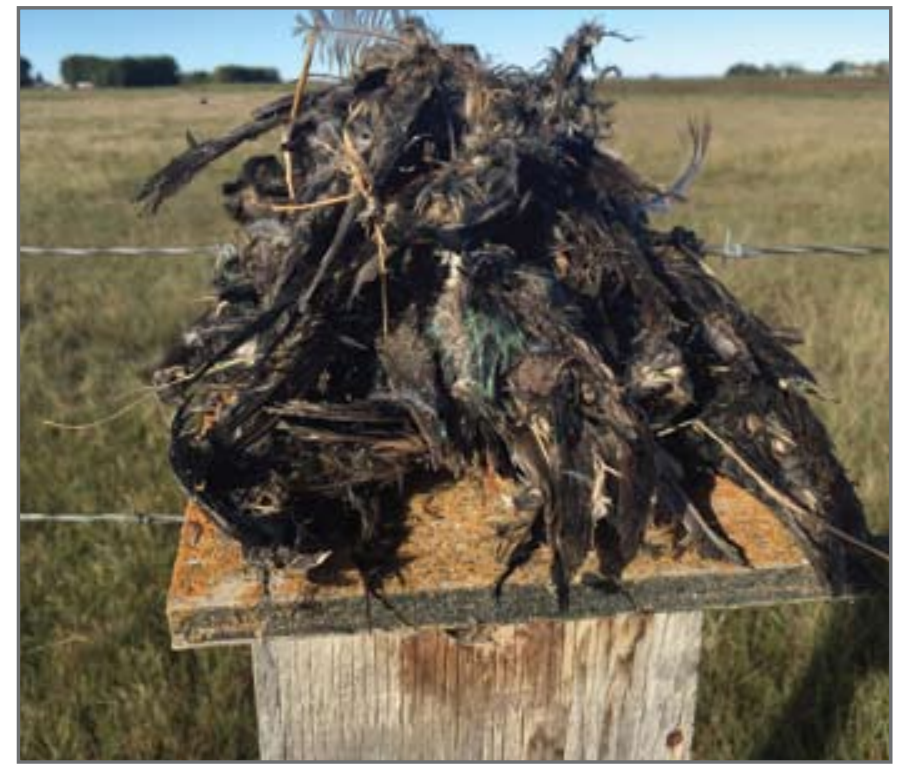

Figure 2: The dead Tree Swallows after being inspected individually for bands. Photo credit: Dick Stauffer 
even more when several swallows huddle together, as they lower their body temperatures and enter a form of torpor. ${ }^{5}$ Too many swallows crowded into one nest-box, however, may result in suffocation of individuals trapped at the bottom of the cluster. This is apparently what happened at the nest-box near Olds, $A B$, but as Donald Stiles noted, 25 dead Tree Swallows in one box must be some kind of a record! Some individuals on top of the cluster may have survived and left the box when the weather improved, before the new nest was constructed over the dead swallows.

How long the swallows were in the box before they died, whether from heat-loss and starvation, or from suffocation, or whether the birds at the bottom of the cluster were the first to die, are not known. In one case in Manitoba, six Tree Swallows that were stacked one on top of the other in an old woodpecker hole were dead, but two other individuals at the bottom of the cluster were alive, but weak; one succumbed soon after removal from the cavity, the other survived long enough to be able to fly away. ${ }^{5}$ Observations have suggested that by the time most swallows have sought shelter under these circumstances they were already weak and possibly close to death. ${ }^{3,5}$ Joining a cluster to reap energetic advantages seems to be balanced by the risks of dying from that association.

1. Dence WA (1946) Tree Swallow mortality from exposure during unseasonable weather. Auk 63:440.

2. Anderson DW (1965) Spring mortality in insectivorous birds. Loon 37:134-135.

3. Sealy SG (1966) Swallow mortality at Moose Mountain. Blue Jay 24:17-18.

4. Smith A, Lane $N$, Patmore $H$, Robinson B, Barnes D, McGowan M (1984) Twentythird annual nestbox report from Brandon, Manitoba. Blue Jay 42:44-46.

5. Weatherhead PJ, Sealy SG, Barclay RMR (1985) Risks of clustering in thermallystressed swallows. Condor 87:443-444.

\section{POETRY}

Lost Poem of Highway 16

Somewhere near Maidstone

By a railway crossing

I saw a big raven

Mantled over a road-mangled meal.

There were two magpies

Up to their usual tricks

Trying to steal a morsel

From their dangerous, stoic cousin.

One'd hop in close

Then the other'd try

Hoping raven would lunge

And the other could dash in.

Raven wasn't buying it

He stood over the kill

Tearing, bolting down meat

Never gave magpies the satisfaction.

Their patience gave first

One got too close

Raven pounced, pinned him

Squeezed a hopeless, terror'd squawk.
Another angry, scared scream

From his victim's mate.

She flew up, round panicked

Their cries futile, past desperation.

Raven lifted his head

Watched her fly and shriek

Then his gory heavy beak

Was over his writhing, flapping prey.

Then, it was strange

He carefully, delicately

Unclenched his talons

Lifted his foot, freed the magpie.

I didn't know magpies

Could fly that fast.

They dissolved into the sky

As light, quick, as a snuffed flamed.

The raven fixed me then

With a bright, straight stare

He went back to his work

And I drove on to mine.

George Grassick

Box 205, Lumsden, SK SOG 3C0

ggrassick@sasktel.net

\section{BEING A BIRD IN NORTH AMERICA: WINNER OF AUTOGRAPHED COPY}

The Winter 2016 issue of Blue Jay included a book review on Robert Alvo's Being a Bird in North America, North of Mexico, Volume 1: Waterfowl to Shorebirds and readers were given the chance to enter to win an autographed copy of the book. Blue Jay is pleased to announce that the winner of the draw is Katharine Schulz of Winnipeg, MB. Congratulations, Katharine!

Being a Bird in North America is available at McNally Robinson in Saskatoon and Winnipeg, on Robert Alvo's website at www.babina.ca and on Amazon.ca.

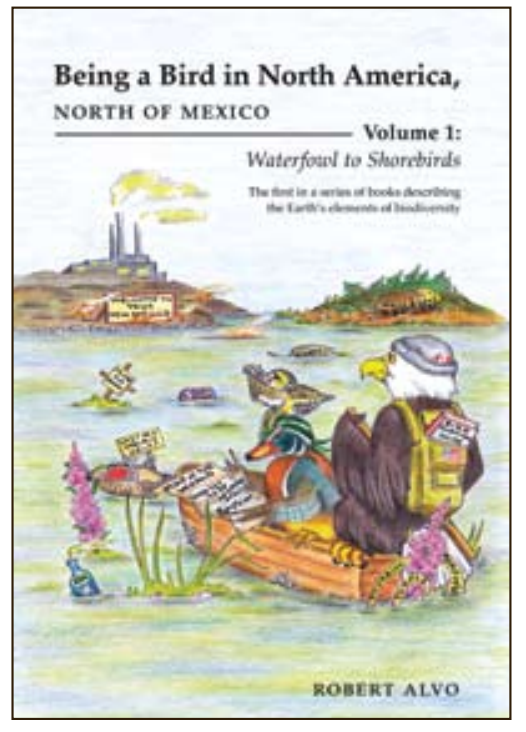

